\title{
Multi-response optimization of cutting parameters in MQL assisted turning of Haynes 25 alloy with Taguchi based grey relational analysis
}

\author{
Tushar Dhote*, Rahul A Mali*, Jitendra Katiyar** and T. V. K. Gupta*** \\ * Department of Mechanical Engineering, Visvesvaraya National Institute of Technology, Nagpur, India. \\ ** Department of Mechanical Engineering, SRM Institute of Science \& Technology, Kattankulathur, Tamil Nadu, India. \\ *** Corresponding Author: tvkgupta@mec.vnit.ac.in
}

$\begin{array}{ll}\text { Submitted } & : 05 / 03 / 2020 \\ \text { Revised } & : 03 / 12 / 2020 \\ \text { Accepted } & : 08 / 12 / 2020\end{array}$

\begin{abstract}
Haynes 25 is a cobalt based superalloy gaining its importance in aerospace, heat treatment applications, chemical handling equipment, commercial gas turbine engines, bearing material, etc. This alloy is featured with low thermal conductivity, wear and corrosion resistance, and strength with good resistance to oxidation at high temperatures. In the present study, optimization of process parameters in turning Haynes 25 alloy with uncoated and coated carbide tools under the minimum quantity lubrication (MQL) using Taguchi based grey relational analysis (GRA) method is attempted. The influence of cutting parameters and nanoparticle concentration on surface roughness, tool wear, cutting, and thrust forces is analyzed to improve the alloy machinability. The work also compares the responses obtained with uncoated and coated tool inserts and analyzes the effect of nanoparticle concentration. Further, the experimental cutting and thrust forces are computed and validated using FE based DEFORM 3D software. The results obtained through simulation are in good accordance with experimental data within an average relative error of about $12 \%$.
\end{abstract}

Keywords: Haynes 25, Grey Relational Analysis, Minimum Quantity Lubrication, DEFORM 3D.

\section{INTRODUCTION}

The recent advances in the manufacturing industry have posed variety of challenges to deliver quality machined parts at reduced cost and increased machinability for difficult to cut materials. The process efficiency can be improved by reducing the machining time which can be achieved with high-speed machining. The phenomenon of thermal softening and chemical stability of tool material occurs in machining hard to cut materials such as superalloys, due to which the cutting speed is hampered. So, it is important to understand and investigate the machinability aspect of hard to cut alloys with appropriate machining parameters and converge to attain a set of optimal parameters. A good machinability is defined as a combination of cutting force, tool temperature; surface roughness, tool wear, power consumption, etc., are all to be low. Optimization of machining parameters improves not only the machining economics but also product quality. Superalloys are categorized according to the base elements like Nickel (Ni), Iron 
(Fe), Cobalt (Co), etc., and in particular, Co-based alloys are gaining importance due to their tendency to work-harden and maintain higher strength at elevated machining temperatures. Some of the commonly used Co based superalloys are Stellite, Haynes 188, Haynes 25, etc.

Machining Haynes 25 alloy with uncoated carbide tools (Sarikaya and Abdulkadir, 2014, 2016) reports that working with cutting speeds beyond $45 \mathrm{~m} / \mathrm{min}$ decreases the surface roughness, which is due to excessive tool wear. The alloy when machined under MQL environment gave better machinability. The optimal cutting parameters were established using Taguchi's signal to noise $(\mathrm{S} / \mathrm{N})$ ratio analysis, which shows lesser tool wear at high cutting speeds because of shortened contact duration between tool and work. The optimal parameters with MQL cooling system (Sarikaya and Abdulkadir, 2015) for achieving flank and notch wear with surface roughness are investigated at different lubrication flow rates. The effect of dry and cryogenic cooling on tool wear in machining Co-based alloys is carried through ANOVA to identify suitable contributing parameters (Sarikaya and Abdulkadir, 2015). The role of MQL on cutting temperature, chip formation and product quality in turning AISI-1040 steel with uncoated carbide tools at different cutting speeds and feed was attempted (Dhar et al., 2006). The authors reported that MQL enables substantial reduction in the cutting temperature, dimensional inaccuracy depending on the levels of cutting speed and feed rate. In this case, the chip formation and chip-tool interaction become more favorable under MQL environment with maximum flank wear in machining with cryogenic cooling was $60 \%$ lower than in dry machining. The cutting tool wear in machining Co-based composite materials (Prasanth et al., 2018) was found to be optimum at $60 \mathrm{~N}$ load, sliding speed of $1 \mathrm{~m} / \mathrm{s}$ and $1000 \mathrm{~m}$ sliding distance while performing wear analysis. The reports concluded that sliding distance affects the wear which contributes to $61.05 \%$. A detailed and cost-effective energy model for a sustainable machining process in turning AISI52100 steel (Khan et al., 2020) has been developed with nanofluid assistance after analyzing the viscosity, thermal conductivity and coefficient of friction. The surface roughness, power and energy consumption, tool life, and cost per part are evaluated and later compared with the present MQL assisted machining. Multiple regression models were developed (Sharma et al., 2019) in turning with MWCNT hybrid nanoparticle MQL environment to measure the temperature and tool wear using RSM. The results evidence an $11 \%$ and $27 \%$ reduction in tool wear and temperature than alumina-based lubricants.

The cutting parameters are correlated with surface roughness and forces in machining AISI 52100 steel with CBN tools using Response surface methodology (RSM) (Bouacha et al., 2010). The results reported that surface roughness is being affected with feed rate and cutting speed, while thrust force was sensitive to work hardness and the tool negative rake angle. The effect of machining parameters and side cutting edge angle on surface roughness and tangential force in dry turning of AISI 1045 steel with multilayer tungsten carbide tools (Noordin et al., 2004) concluded that feed rate has a significant role. The cutting speed doesn't influence the cutting forces in turning MDN250 steel (Lalwani et al., 2008), while the thrust forces are affected by feed rate and depth of cut; also, the surface roughness is highly affected by depth of cut. Machining with CVD and PVD coated tools with TiCN coating to estimate the surface roughness (Cakir et al., 2009) illustrates that better finish is achieved with PVD coated tools. The surface roughness increases with feed rate and decreases with nose radius while machining AISI 410 steel (Ashvin and Nanavati, 2013). A second order model developed to predict the surface roughness parameters, namely, $\mathrm{R}_{\mathrm{a}}, \mathrm{R}_{\mathrm{q}}$, and $\mathrm{R}_{\mathrm{ms}}$ using RSM (Routaraetal., 2012) has reported that better finish is observed at higher cutting speeds and depth of cut, while the roughness increases with feed rate.

Today, manufacturing sectors are looking for alternative tools to understand the metal cutting process for improving quality and machining performance at minimum cost. One such alternative is the finite element (FE) based machining simulation. These simulations are used to estimate and predict the chip formation, tool wear, cutting forces, residual stresses, temperature, etc. in machining. Lagrangian method (Rityuj et al., 2017) in DEFORM 3D software to predict cutting forces and temperatures is used in turning AISI H13 with ceramic tool that saves time and consumables without performing the actual experiments. The cutting forces in turning TC4 alloy (Chen, et al., 2006) are estimated in DEFORM 3D. The experimental results are validated with FE-based DEFORM 3D simulation in 
machining Ti6Al4V alloy (Satyanarayana et al., 2013) and further performed multiobjective optimization using Genetic Algorithms that have given a relative error of about $9.07 \%$. The tool geometry is optimized to achieve minimum flank wear and surface roughness (Tamizharasan et al., 2012). The FE-based simulation (Rahul Mali et al., 2019) was carried using DEFORM 3D in dry turning of Aluminum 7075 alloy to validate the estimated forces with experiments.

Not much literature is available in any form to predict cutting forces and temperature in machining Haynes 25 alloy. The present work is an attempt to study Haynes 25 machining with minimum quality lubrication (MQL) that can improve the surface quality and tool life. The Taguchi-Grey relational analysis is used to develop a mathematical model for parametric optimization and DEFORM 3D for simulating the forces.

\section{MATERIALS, MEASURMENTS, and METHODOLOGY}

\section{A. Materials}

Haynes 25 alloy has good properties like high-temperature strength, resistance to oxidation, etc. and has variety of applications in aerospace, high temperature applications, etc. with chemical composition mentioned in Table 1. In the experimentation, a cylindrical rod of $25 \mathrm{~mm}$ dia. and $300 \mathrm{~mm}$ length is taken as the input raw material and a turning length of $5 \mathrm{~mm}$ is considered for analysis. An MQL system (KENCO make) is used for experimentation. The high temperatures inducted in hard material machining makes the work-tool material interface reacts with each other causing high tool wear. The problem of chemical reaction can be avoided by applying coatings like $\mathrm{TiC}_{2} \mathrm{Al}_{2} \mathrm{O}_{3}, \mathrm{TiN}_{\text {, }}$ etc. on the insert surface creating a thermal barrier that impedes the interface reaction which also increases the tool life. In the present work, CCMT09T308MP, grade WS10PT, PVD coated inserts (WIDIA-made), and CCMT09T308 uncoated inserts having two cutting edges are used for experimentation. Later confirmation tests are performed with uncoated and coated inserts to estimate the improvement in performance. Table 2 gives the details of cutting inserts that has a rake angle, major edge cutting angle, cutting edge inclination angle, and nose radius as $7^{\circ}, 75^{\circ}, 6^{\circ}$, and 0.8 $\mathrm{mm}$, respectively.

Table 1. Chemical composition of Haynes 25 (Sarikaya, 2015).

\begin{tabular}{|c|c|c|c|c|c|c|c|c|c|}
\hline Material & $\mathrm{C}$ & $\mathrm{Cr}$ & $\mathrm{Fe}$ & $\mathrm{Ni}$ & $\mathrm{P}$ & $\mathrm{S}$ & $\mathrm{Si}$ & $\mathrm{W}$ & $\mathrm{Co}$ \\
\hline \%weight & 0.10 & 20.30 & 1.58 & 10.20 & $<0.005$ & 0.0008 & 0.01 & 14.7 & Balance \\
\hline
\end{tabular}

Table 2. Cutting tool insert details.

\begin{tabular}{|c|c|}
\hline ISO Catalog Number: CCMT09T308MP & Insert Material: Tungsten Carbide \\
\hline Insert Shape: Rhombic & Coating: PVD \\
\hline Chip Breaker: UF & Grade: WS10PT \\
\hline Insert Length: $9.70 \mathrm{~mm}$ & Insert Thickness: $3.97 \mathrm{~mm}$ \\
\hline
\end{tabular}




\section{B. Cuttıng Fluid}

Coconut oil was chosen as a cutting fluid with added graphite nanopowder in different wt $\%(0.25,0.75$, and 1.25), respectively, to improve the quality of cut. The particle size is 50-100 nm (supplied by Nano Research Lab, Bangalore, India) and the homogeneous mixing of coconut oil and the nanopowders are done by stirring process at 1000 RPM for $30 \mathrm{~min}$. Figure 1 shows the mixture homogeneity as observed using transmission electron microscopy (TEM).

\section{Mınımum Quality Lubricatıon}

The fabricated cutting fluid is further used in the machining interface by MQL system. In this present study, the MQL system reservoir has a capacity of 5L from KENCO lubrication. The input air pressure is maintained within 3 to $5 \mathrm{~kg} / \mathrm{cm} 2$ with a relief valve and the discharge of oil and air can be adjusted with a flow adjustment valve, which is maintained at $60 \mathrm{ml} / \mathrm{hr}$.

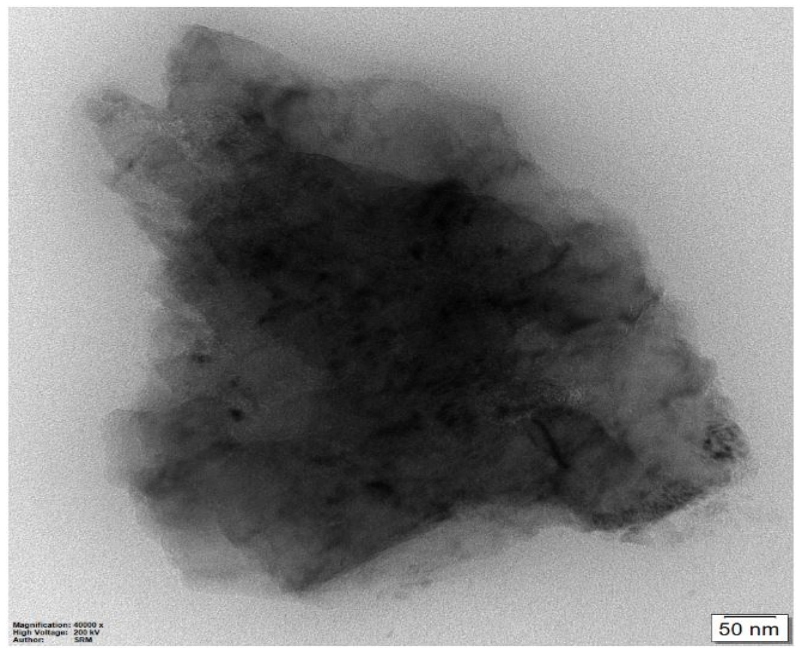

Figure 1. TEM image of coconut oil mixed with $0.75 \mathrm{wt} \%$ graphite nanopowder.

\section{Measurements}

The cutting forces are measured with Kistler 9257B, a 6-component dynamometer having maximum measuring capacity of $10 \mathrm{kN}$ with $5 \mathrm{pC} / \mathrm{N}$ sensitivity. Mitutoyo Surftest SJ-410 is used for roughness measurement at a speed of $0.5 \mathrm{~mm} / \mathrm{s}$. The tool wear is measured with a USB digital microscope (Model No. UM5-GSAS 225) having a magnification of 1600-1200 pixels.

\section{E. Methodology}

A systematic experimental plan is designed based on Taguchi's 4 parameters, 3 levels with L9 orthogonal array and accordingly tests being carried out. The responses are analyzed using Grey relational analysis (GRA) method for process optimization. Speed, feed, depth of cut and nanoparticle concentration are the input parameters while surface roughness $\left(\mathrm{R}_{\mathrm{a}}\right.$ in $\left.\mu \mathrm{m}\right)$, tool wear $\left(\mathrm{VB}_{\max }\right.$ in $\left.\mathrm{mm}\right)$, cutting force $\left(\mathrm{F}_{\mathrm{c}}\right.$ in $\left.\mathrm{N}\right)$ and thrust force $\left(\mathrm{F}_{t}\right.$ in $\left.\mathrm{N}\right)$ are measured responses. The confirmatory tests are performed with uncoated and coated inserts as per the optimal parameters. The experimental forces are validated with FE based DEFORM 3D simulation software. 


\section{EXPERIMENTATION, GREY RELATIONAL ANALYSIS, CONFIRMATORY TEST}

\section{A. Experimentation}

All the tests are performed on a conventional lathe machine (Model No. 141, PSG make) having a maximum spindle speed of $1600 \mathrm{rpm}$. A total of 18 experiments ( 9 each for coated and uncoated inserts) are performed with corresponding levels mentioned in Table 3. Figure 2 shows the experimental setup, while the measurements are summarized in Tables 4, 5 .

Table 3. Process parameters and levels.

\begin{tabular}{|c|c|}
\hline Process parameters, Symbols & Levels $(1,2,3)$ \\
\hline Speed (rpm) A & $800,1150,1600$ \\
\hline Feed rate (mm/rev) B & $0.1,0.16,0.2$ \\
\hline Depth of cut (mm) C & $0.1,0.25,0.5$ \\
\hline Nano Particle (h-BN) conc. (\%) D & $0.25,0.75,1.25$ \\
\hline
\end{tabular}

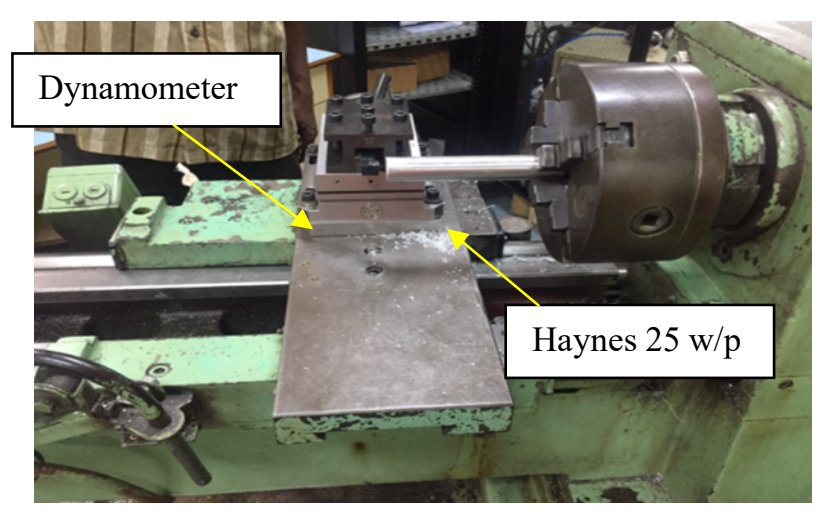

Figure 2. Experimental Setup.

Table 4. Responses measured with uncoated tool.

\begin{tabular}{|c|c|c|c|c|c|c|c|c|}
\hline $\begin{array}{c}\text { Test } \\
\text { No. }\end{array}$ & $\begin{array}{c}\text { Speed } \\
(\mathrm{rpm})\end{array}$ & $\begin{array}{c}\text { Feed rate } \\
(\mathrm{mm} / \mathrm{rev})\end{array}$ & $\begin{array}{c}\text { DOC } \\
(\mathrm{mm})\end{array}$ & Con. $(\%)$ & $\mathrm{R}_{\mathrm{a}}(\mu \mathrm{m})$ & $\begin{array}{c}\mathrm{VB}_{\max } \\
(\mathrm{mm})\end{array}$ & $\mathrm{F}_{\mathrm{c}}(\mathrm{N})$ & $\mathrm{F}_{\mathrm{t}}(\mathrm{N})$ \\
\hline 1 & 800 & 0.10 & 0.10 & 0.25 & 1.738 & 0.196 & 125 & 33 \\
\hline 2 & 800 & 0.16 & 0.25 & 0.75 & 0.886 & 0.167 & 256 & 65 \\
\hline 3 & 800 & 0.20 & 0.50 & 1.25 & 1.492 & 0.190 & 390 & 92 \\
\hline 4 & 1150 & 0.10 & 0.25 & 1.25 & 1.343 & 0.162 & 192 & 62 \\
\hline 5 & 1150 & 0.16 & 0.50 & 0.25 & 1.120 & 0.178 & 434 & 140 \\
\hline 6 & 1150 & 0.20 & 0.10 & 0.75 & 0.871 & 0.167 & 167 & 29 \\
\hline 7 & 1600 & 0.10 & 0.50 & 0.75 & 0.954 & 0.186 & 266 & 88 \\
\hline 8 & 1600 & 0.16 & 0.10 & 1.25 & 1.454 & 0.176 & 115 & 17 \\
\hline 9 & 1600 & 0.20 & 0.25 & 0.25 & 0.436 & 0.194 & 261 & 69 \\
\hline
\end{tabular}


Table 5. Responses measured with coated tool.

\begin{tabular}{|c|c|c|c|c|c|c|c|c|}
\hline $\begin{array}{c}\text { Test } \\
\text { No. }\end{array}$ & $\begin{array}{c}\text { Speed } \\
(\mathrm{rpm})\end{array}$ & $\begin{array}{c}\text { Feed rate } \\
(\mathrm{mm} / \mathrm{rev})\end{array}$ & $\begin{array}{c}\text { DOC } \\
(\mathrm{mm})\end{array}$ & Con. $(\%)$ & $\mathrm{Ra}(\mu \mathrm{m})$ & $\begin{array}{c}\mathrm{VB}_{\max } \\
(\mathrm{mm})\end{array}$ & $\mathrm{F}_{\mathrm{c}}(\mathrm{N})$ & $\mathrm{F}_{\mathrm{t}}(\mathrm{N})$ \\
\hline 1 & 800 & 0.10 & 0.10 & 0.25 & 0.447 & 0.120 & 84 & 23 \\
\hline 2 & 800 & 0.16 & 0.25 & 0.75 & 0.790 & 0.128 & 235 & 52 \\
\hline 3 & 800 & 0.20 & 0.50 & 1.25 & 1.133 & 0.113 & 387 & 90 \\
\hline 4 & 1150 & 0.10 & 0.25 & 1.25 & 0.367 & 0.140 & 168 & 42 \\
\hline 5 & 1150 & 0.16 & 0.50 & 0.25 & 0.830 & 0.155 & 336 & 110 \\
\hline 6 & 1150 & 0.20 & 0.10 & 0.75 & 1.185 & 0.110 & 144 & 22 \\
\hline 7 & 1600 & 0.10 & 0.50 & 0.75 & 0.368 & 0.102 & 247 & 70 \\
\hline 8 & 1600 & 0.16 & 0.10 & 1.25 & 0.699 & 0.091 & 125 & 21 \\
\hline 9 & 1600 & 0.20 & 0.25 & 0.25 & 0.855 & 0.091 & 246 & 45 \\
\hline
\end{tabular}

\section{B. Grey Relational Analysis}

GRA method is used in the present analysis which doesn't require an equation or a model correlating inputoutput parameters to obtain optimum parameters. In GRA, the responses are normalized between 0 and 1 , known as grey relational generation from which the Grey relational coefficients (GRCs) are calculated to express the relationship between desired and actual responses. The grey relational grades (GRGs) are computed by averaging the GRCs of each response. Evaluation of the multiobjective responses is done through GRG, which is finally converted into a single grade. In the present study, lower the better criterion has been used to generate the grades, which are calculated as follows:

$$
x_{i}(k)=\frac{\max y_{i}(k)-y_{i}(k)}{\max i_{i}(k)-\min y_{i}(k)}
$$

where $x_{i}(k)$ is the value after the grey relational generation, $\min y_{i}(k)$ is the smallest value of $y_{i}(k)$ for $k^{\text {th }}$ response, and $\max y_{i}(k)$ is the largest value of $y_{i}(k)$ for $k^{\text {th }}$ response. An ideal sequence is $\left[x_{0}(k),(k=1,2,3,4)\right]$ for the responses. The GRC $\varepsilon_{i}(k)$ is calculated as:

$$
\varepsilon_{i}(k)=\frac{\Delta_{\min }+\varphi \Delta_{\max }}{\Delta_{0 i}(k)+\varphi \Delta_{\max }}
$$

where $\Delta_{0 i}=\left\|x_{0}(k)-x_{i}(k)\right\|=$ difference of the absolute value between $x_{0}(k)$ and $x_{i}(k)$.

The overall GRG is calculated by averaging GRCs corresponding to the selected responses, with an objective to show the degree of relation between the sequences [ $x_{0}(k)$ and $x_{i}(k), \mathrm{i}=1$ to 9 ]. The GRG is calculated as 
148 Multi-response optimization of cutting parameters in MQL assisted turning of Haynes 25 alloy with Taguchi based grey relational analysis

$\gamma_{i}=\frac{1}{n} \sum_{k=1}^{n} \xi_{i}(k)$

where $\mathrm{n}=$ number of responses.

Accordingly, GRCs, GRGs and the ranks are calculated that are mentioned in Tables 6 and 7 for uncoated and coated inserts. The main effect plots are shown in Fig. 3 and 4 as obtained in MINTAB software. This represents the input-output correlations for uncoated and coated inserts respectively. The ranks obtained based on GRGs shows that $\mathrm{A} 2 \mathrm{~B} 3 \mathrm{C} 1 \mathrm{D} 2$ and A3B2C1D3 are optimum input parameters combination for uncoated and coated inserts.

Table 6. GRC, GRG and Rank (uncoated).

\begin{tabular}{|c|c|c|c|c|c|c|c|c|c|c|c|c|c|}
\hline \multicolumn{4}{|c|}{ Responses } & \multicolumn{4}{|c|}{ Grey Relational Generation } & \multicolumn{4}{|c|}{ Grey Relation Coefficient } & \multirow{2}{*}{ GRG } & \multirow{2}{*}{ Rank } \\
\hline $\mathrm{R}_{\mathrm{a}}$ & $\mathrm{VB}_{\max }$ & $\mathrm{F}_{\mathrm{c}}$ & $\mathrm{F}_{\mathrm{t}}$ & $\mathrm{R}_{\mathrm{a}}$ & $\mathrm{VB}_{\max }$ & $\mathrm{F}_{\mathrm{c}}$ & $\mathrm{F}_{\mathrm{t}}$ & $\mathrm{R}_{\mathrm{a}}$ & $\mathrm{VB}_{\max }$ & $\mathrm{F}_{\mathrm{c}}$ & $\mathrm{F}_{\mathrm{t}}$ & & \\
\hline 1.738 & 0.196 & 125 & 33 & 0.000 & 0.000 & 0.969 & 0.870 & 0.333 & 0.333 & 0.941 & 0.794 & 0.600 & 6 \\
\hline 0.886 & 0.167 & 256 & 65 & 0.654 & 0.853 & 0.558 & 0.610 & 0.591 & 0.773 & 0.531 & 0.562 & 0.614 & 4 \\
\hline 1.492 & 0.190 & 390 & 92 & 0.189 & 0.176 & 0.138 & 0.390 & 0.381 & 0.378 & 0.367 & 0.451 & 0.394 & 9 \\
\hline 1.343 & 0.162 & 192 & 62 & 0.303 & 1.000 & 0.759 & 0.634 & 0.418 & 1.000 & 0.674 & 0.577 & 0.667 & 3 \\
\hline 1.120 & 0.178 & 434 & 140 & 0.475 & 0.529 & 0.000 & 0.000 & 0.488 & 0.515 & 0.333 & 0.333 & 0.417 & 8 \\
\hline 0.871 & 0.167 & 167 & 29 & 0.666 & 0.853 & 0.837 & 0.902 & 0.599 & 0.773 & 0.754 & 0.837 & 0.741 & 1 \\
\hline 0.954 & 0.186 & 266 & 88 & 0.602 & 0.294 & 0.527 & 0.423 & 0.557 & 0.415 & 0.514 & 0.464 & 0.487 & 7 \\
\hline 1.454 & 0.176 & 115 & 17 & 0.218 & 0.588 & 1.000 & 1.000 & 0.390 & 0.548 & 1.000 & 1.000 & 0.735 & 2 \\
\hline 0.436 & 0.194 & 261 & 69 & 1.000 & 0.059 & 0.542 & 0.577 & 1.000 & 0.347 & 0.522 & 0.542 & 0.603 & 5 \\
\hline
\end{tabular}

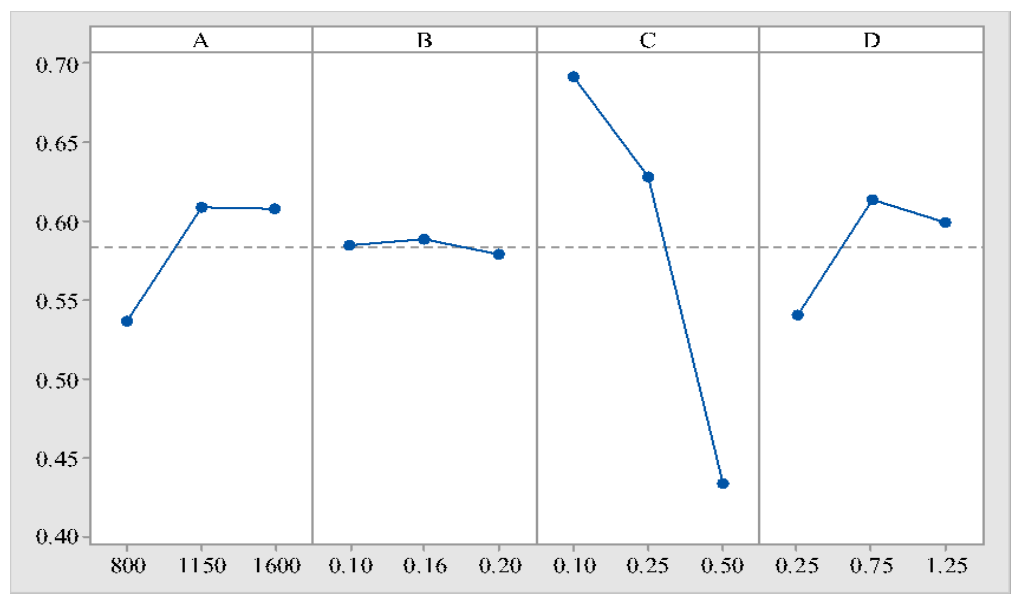

Figure 3. Main effects plot for GRG (uncoated). 
Table 7. GRC, GRG and Rank (coated).

\begin{tabular}{|c|c|c|c|c|c|c|c|c|c|c|c|c|c|}
\hline \multicolumn{4}{|c|}{ Responses } & \multicolumn{4}{|c|}{ Grey Relational Generation } & \multicolumn{4}{|c|}{ Grey Relation Coefficient } & \multirow{2}{*}{ GRG } & \multirow{2}{*}{ Rank } \\
\hline $\mathrm{R}_{\mathrm{a}}$ & $\mathrm{VB}_{\max }$ & $\mathrm{F}_{\mathrm{c}}$ & $\mathrm{F}_{\mathrm{t}}$ & $\mathrm{R}_{\mathrm{a}}$ & $\mathrm{VB}_{\max }$ & $\mathrm{F}_{\mathrm{c}}$ & $\mathrm{F}_{\mathrm{t}}$ & $\mathrm{R}_{\mathrm{a}}$ & $\mathrm{VB}_{\max }$ & $\mathrm{F}_{\mathrm{c}}$ & $\mathrm{F}_{\mathrm{t}}$ & & \\
\hline 0.447 & 0.120 & 84 & 23 & 0.902 & 0.547 & 1.000 & 0.978 & 0.836 & 0.525 & 1.000 & 0.957 & 0.829 & 2 \\
\hline 0.790 & 0.128 & 235 & 52 & 0.483 & 0.422 & 0.502 & 0.652 & 0.492 & 0.464 & 0.501 & 0.589 & 0.511 & 7 \\
\hline 1.133 & 0.113 & 387 & 90 & 0.064 & 0.656 & 0.000 & 0.225 & 0.348 & 0.593 & 0.333 & 0.392 & 0.417 & 8 \\
\hline 0.367 & 0.140 & 168 & 42 & 1.000 & 0.234 & 0.723 & 0.764 & 1.000 & 0.395 & 0.643 & 0.679 & 0.679 & 3 \\
\hline 0.830 & 0.155 & 336 & 110 & 0.434 & 0.000 & 0.168 & 0.000 & 0.469 & 0.333 & 0.375 & 0.333 & 0.378 & 9 \\
\hline 1.185 & 0.110 & 144 & 22 & 0.000 & 0.703 & 0.802 & 0.989 & 0.333 & 0.627 & 0.716 & 0.978 & 0.664 & 5 \\
\hline 0.368 & 0.102 & 247 & 70 & 0.999 & 0.828 & 0.462 & 0.449 & 0.998 & 0.744 & 0.482 & 0.476 & 0.675 & 4 \\
\hline 0.699 & 0.091 & 125 & 21 & 0.594 & 1.000 & 0.865 & 1.000 & 0.552 & 1.000 & 0.787 & 1.000 & 0.835 & 1 \\
\hline 0.855 & 0.091 & 246 & 45 & 0.403 & 1.000 & 0.465 & 0.730 & 0.456 & 1.000 & 0.483 & 0.650 & 0.647 & 6 \\
\hline
\end{tabular}

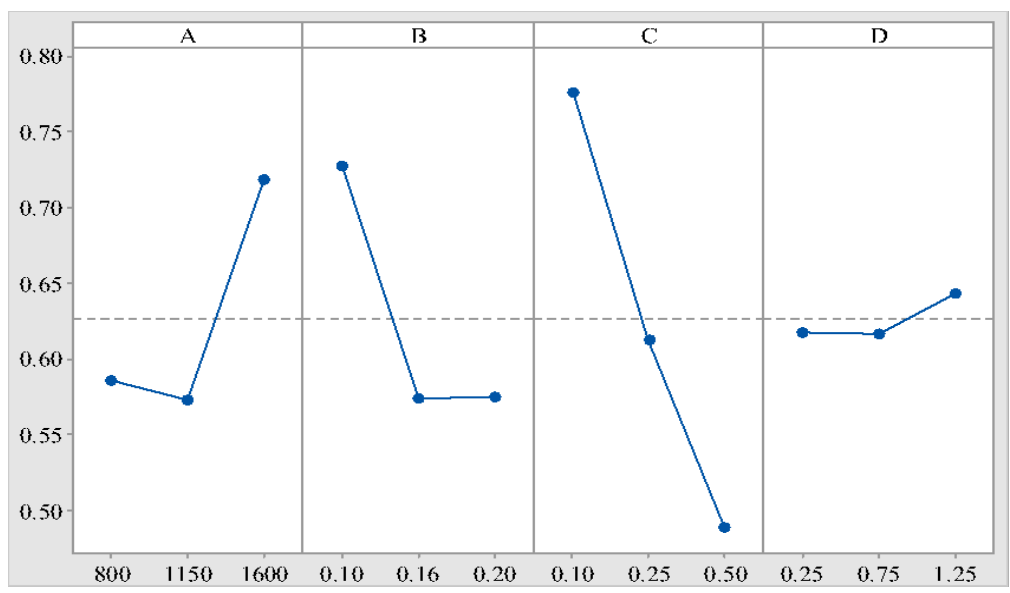

Figure 4. Main effects plot for GRG (coated).

\section{Confirmatory Tests}

Experiments are performed for the optimum input parameters and corresponding responses are measured for both the cases (uncoated, coated). On identification of the optimal set, confirmatory tests are performed to predict and verify the performance improvement in the responses. The estimated GRG, $\hat{\gamma}$ at optimum process parameters is calculated as: 
where $\gamma_{m}$ is the total mean GRG, $\gamma_{i}$ is mean GRG at the optimum level. The responses (surface roughness, flank wear, cutting, and thrust forces) measured for the optimized experimental conditions are mentioned in Table 8 . The results show that the confirmation tests agree well with the predicted values showing an improvement of $24.5 \%$ in GRG. This improvement in the experimental results over the initial design parameters confirms the validity of Taguchi method coupled with GRA. Similarly, confirmation tests are performed with coated inserts at optimal conditions to validate the experimental data and the responses are summarized in Table 9 shows an improvement of $6.4 \%$ in GRG.

Table 8. Result of the confirmation experiment (uncoated).

\begin{tabular}{|c|c|c|c|}
\hline \multirow{2}{*}{ Responses } & \multirow{2}{*}{$\begin{array}{c}\text { Initial design } \\
\text { parameters }\end{array}$} & Predicted & Experimental \\
\cline { 3 - 4 } & A1B1C1D1 & A2B2C1D2 & A2B2C1D2 \\
\hline Parameter Level & 1.738 & & 0.796 \\
\hline Surface roughness & 0.196 & & 0.170 \\
\hline Tool wear & 125 & & 151 \\
\hline Cutting force & 33 & 0.751 & 28 \\
\hline Thrust force & 0.600 & & 0.747 \\
\hline GRG & & & $24.5 \%$ \\
\hline Improvement in GRG & & & \multirow{2}{*}{ Opesign parameters } \\
\hline
\end{tabular}

Table 9. Result of the confirmation experiment (coated).

\begin{tabular}{|c|c|c|c|}
\hline \multirow{2}{*}{ Responses } & \multirow{2}{*}{$\begin{array}{c}\text { Initial design } \\
\text { parameters }\end{array}$} & Optimal design parameters \\
\cline { 3 - 4 } & A1B1C1D1 & A3B3C1D2 & A3B3C1D2 \\
\hline Parameter Level & 0.477 & & 0.548 \\
\hline Surface roughness & 0.120 & & 0.085 \\
\hline Tool wear & 84 & & 114 \\
\hline Cutting force & 23 & 0.9212 & 17 \\
\hline Thrust force & 0.829 & & 0.882 \\
\hline GRG & & & $6.4 \%$ \\
\hline Improvement in GRG & & & Experimental \\
\hline
\end{tabular}




\section{SIMULATION MODELING}

The FE based simulation of cutting process is carried using DEFORM 3D machining software to estimate cutting and thrust forces. The 3D model of the insert is generated in CATIA V5 software with dimensioning module, as shown in Fig. 5. The CAD model is imported to DEFORM ${ }^{\mathrm{TM}} 3 \mathrm{D}$ in STEP format for further analysis.

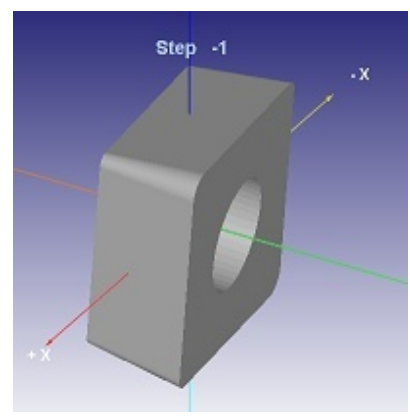

Figure 5. CAD model of tool insert.

The work material in metal cutting is subjected to high plastic strains as $1-5$; strain rates of $10^{3}-10^{6} \mathrm{~s}^{-1}$ and temperatures of the order of $1500^{\circ} \mathrm{C}$, respectively, based on tool and work combination. The challenging task in metal cutting simulation is access to these parameters in relation to strength of the deforming material by conventional material tests. The flow stress of a material is represented with the Johnson-Cook material model in terms of strain, strain rate, and temperature, where the constants can be obtained from the tests carried with Split Hopkinson Pressure Bar (SHPB) or ballistic impact tests. The constitutive material model given by Eq (5) is used with Haynes 25 alloy constants mentioned in Table 10, which is used as material model input for simulation.

$\bar{\sigma}=\left[A+B \varepsilon^{n}\right] *\left[1+c \ln \frac{\bar{\varepsilon}}{\overline{\varepsilon_{0}}}\right] *\left[1-\left(\frac{T-T_{r}}{T_{m}-T_{r}}\right)\right]$

Where

$$
-
$$

$\sigma:$ Flow stress

$\varepsilon:$ Equivalent plastic strain

A: Yield stress constant

$\varepsilon$ : Strain rate

B : Strain hardening coefficient

$\varepsilon_{0}$ Reference strain rate

$\mathrm{n}$ : Strain hardening exponent

$\mathrm{T}:$ Temperature

$C$ : Strain rate dependence coefficient

$\mathrm{T}_{\mathrm{r}}$ : Room Temperature

$m$ : Temperature dependence coefficient

$\mathrm{T}_{\mathrm{m}}$ : Melting Temperature

Table 10. Johnson-Cook model constants for Haynes 25 (Hickman, et al., 2017).

\begin{tabular}{|c|c|c|c|c|c|c|c|}
\hline $\mathrm{A}(\mathrm{MPa})$ & $\mathrm{B}(\mathrm{MPa})$ & $\mathrm{C}$ & $\mathrm{n}$ & $\mathrm{m}$ & $\mathrm{T}_{\mathrm{r}}$ & $\mathrm{T}_{\mathrm{m}}$ & $\overline{\boldsymbol{\varepsilon}_{0}}$ \\
\hline 455 & 2475 & 0.2375 & 0.9 & 0.725 & 20 & 1455 & 0.001 \\
\hline
\end{tabular}


In metal cutting, friction plays an important role by affecting the chip geometry, built edge formation, cutting temperature, and tool wear. In the present work, the frictional force defined by Coulomb's law is given in Eqn. (6), where a shear friction factor of 0.6 is considered.

$f_{s}=\mu \sigma_{t}$

Simulations are performed in DEFORM 3D with process parameters mentioned in Table 11 along with other essential input variables (speed, feed rate, and depth of cut) as per Table 3. The modulus of elasticity and thermal conductivity of Haynes 25 at different temperatures mentioned in Table 12 are given as input for simulation. A size ratio of 4 for insert and 7 for workpiece material are considered. Meshing is done with a tetrahedral element of 25000 mesh size for both workpiece and insert. In the present simulation, the workpiece is treated as plastic material and insert as rigid material. For a cutting (turning) length of $5 \mathrm{~mm}$ and ensuring proper contact between the tool and workpiece, simulation steps of 500 are taken for processing. The flow stresses for different temperatures, strain, and strain rates of $0.00001 \mathrm{~s}^{-1}, 0.001 \mathrm{~s}^{-1}, 0.1 \mathrm{~s}^{-1}$ are considered separately.

Table 11. Process parameters.

\begin{tabular}{|c|c|}
\hline Environment temperature $\left({ }^{\circ} \mathrm{C}\right)$ & 30 \\
\hline Shear friction coefficient & 0.6 \\
\hline Heat transfer coefficient $\left(\mathrm{N} / \mathrm{sec} / \mathrm{mm} /{ }^{\circ} \mathrm{C}\right)$ & 45 \\
\hline Convection coefficient & 0.2 \\
\hline
\end{tabular}

Table 12. Modulus of elasticity and Thermal conductivity for Haynes 25.

\begin{tabular}{|c|c|c|}
\hline Temp. $\left({ }^{\circ} \mathrm{C}\right)$ & $\begin{array}{c}\text { Modulus of Elasticity } \\
(\mathrm{GPa})\end{array}$ & $\begin{array}{c}\text { Thermal Conductivity } \\
\left(\mathrm{W} / \mathrm{m}^{\circ} \mathrm{C}\right)\end{array}$ \\
\hline 25 & 225 & 10.5 \\
\hline 100 & 222 & 12.0 \\
\hline 200 & 214 & 14.0 \\
\hline 300 & 204 & 15.9 \\
\hline 400 & 197 & 17.7 \\
\hline 500 & 188 & 19.5 \\
\hline 600 & 181 & 21.2 \\
\hline 700 & 174 & 22.9 \\
\hline 800 & 163 & 24.5 \\
\hline 900 & 154 & 26.0 \\
\hline 1000 & 146 & 27.5 \\
\hline
\end{tabular}


All the simulations of machining with uncoated inserts are carried as per the experimental runs to analyze the variation in cutting and thrust forces with process parameters. A sample image of the force simulation (test run 9 , uncoated insert) is given in Fig. 6, while the simulated cutting and thrust forces for test run 2 are plotted in Fig. 7.

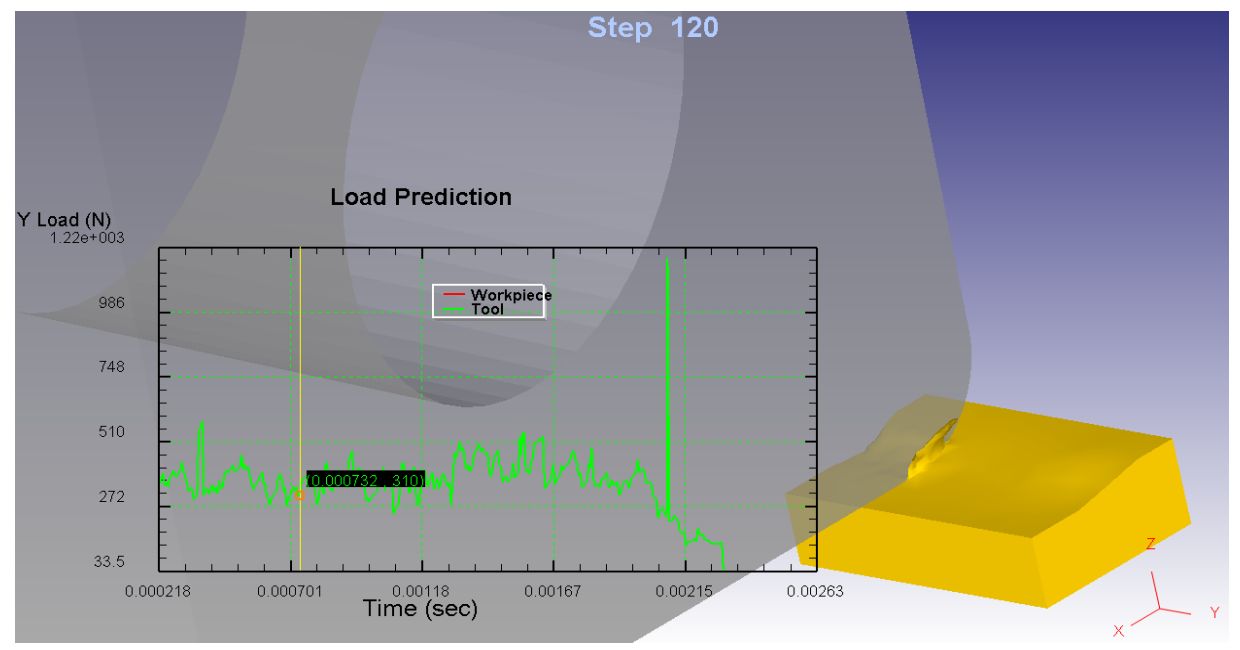

Figure 6. Simulated Force from DEFORM 3D.

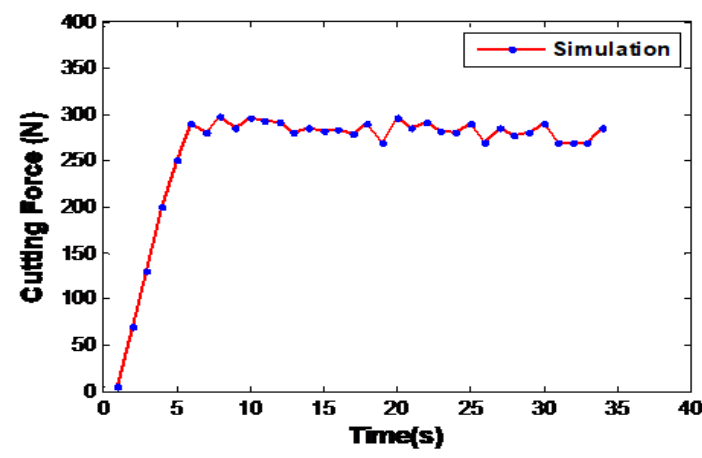

(a)

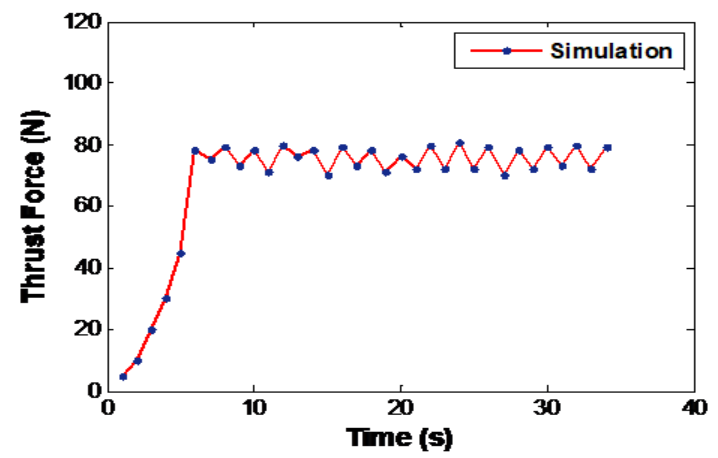

(b)

Figure 7. Simulated (a) Cutting force (b) Thrust force ( $800 \mathrm{rpm}, 0.16 \mathrm{~mm} / \mathrm{rev}, 0.25 \mathrm{~mm}$ ).

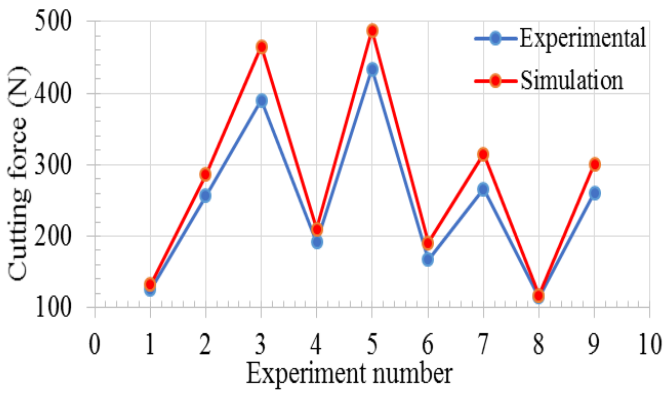

(a)

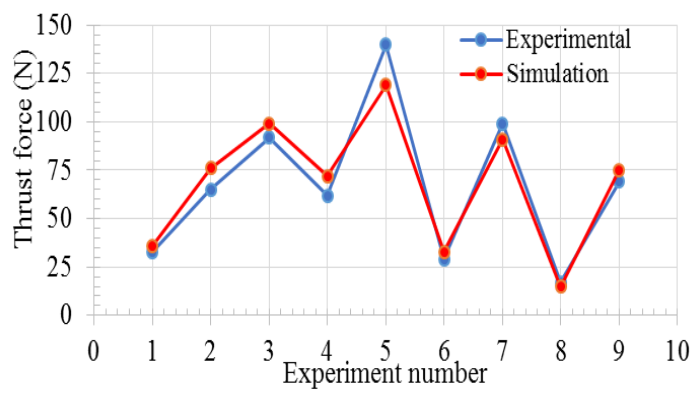

(b)

Figure 8. Comparison of simulated and experimental (a) Cutting force (b) Thrust force. 
154 Multi-response optimization of cutting parameters in MQL assisted turning of Haynes 25 alloy with Taguchi based grey relational analysis

The graphs plotted in Fig. 8 show the comparison of experimental and simulated forces and the results are summarized in Table 13 for uncoated inserts machining. An average relative error of $12.40 \%$ in cutting forces and $11.84 \%$ in thrust forces is obtained.

Table 13. Experimental and simulation forces (uncoated).

\begin{tabular}{|c|c|c|c|c|c|c|c|c|c|}
\hline \multirow[b]{2}{*}{ Exp. No } & \multicolumn{3}{|c|}{ Process Parameters } & \multicolumn{2}{|c|}{ Experimental } & \multicolumn{2}{|c|}{ Simulation } & \multicolumn{2}{|c|}{ Relative Error (\%) } \\
\hline & Speed & $\begin{array}{c}\text { Feed } \\
\text { rate }\end{array}$ & DOC & $\mathrm{F}_{\mathrm{c}}$ & $\mathrm{F}_{\mathrm{t}}$ & $\mathrm{F}_{\mathrm{c}}$ & $\mathrm{F}_{\mathrm{t}}$ & $\mathrm{F}_{\mathrm{c}}$ & $\mathrm{F}_{\mathrm{t}}$ \\
\hline 1 & 800 & 0.10 & 0.10 & 125 & 33 & 132 & 36 & 5.60 & 9.09 \\
\hline 2 & 800 & 0.16 & 0.25 & 256 & 65 & 286 & 76 & 11.71 & 16.92 \\
\hline 3 & 800 & 0.20 & 0.50 & 390 & 92 & 465 & 99 & 19.23 & 7.60 \\
\hline 4 & 1150 & 0.10 & 0.25 & 192 & 62 & 210 & 72 & 9.37 & 16.12 \\
\hline 5 & 1150 & 0.16 & 0.50 & 434 & 140 & 488 & 119 & 12.44 & 17.64 \\
\hline 6 & 1150 & 0.20 & 0.10 & 167 & 29 & 191 & 33 & 14.37 & 13.79 \\
\hline 7 & 1600 & 0.10 & 0.50 & 266 & 29 & 315 & 91 & 18.42 & 3.40 \\
\hline 8 & 1600 & 0.16 & 0.10 & 115 & 17 & 117 & 15 & 1.73 & 13.33 \\
\hline 9 & 1600 & 0.20 & 0.25 & 261 & 69 & 301 & 75 & 18.77 & 8.69 \\
\hline \multicolumn{8}{|c|}{ Average Relative Error } & 12.40 & 11.84 \\
\hline
\end{tabular}

Similarly, the simulation studies are also carried for the tests performed with coated inserts under the same experimental conditions. The simulated cutting and thrust forces for test run 2 are shown in Fig. 9, while Fig. 10 shows the comparison of simulated and experimental cutting and thrust forces. In this case, the average relative error is $12.19 \%$ in cutting forces and $6.05 \%$ in thrust forces is observed as mentioned in Table 14 .

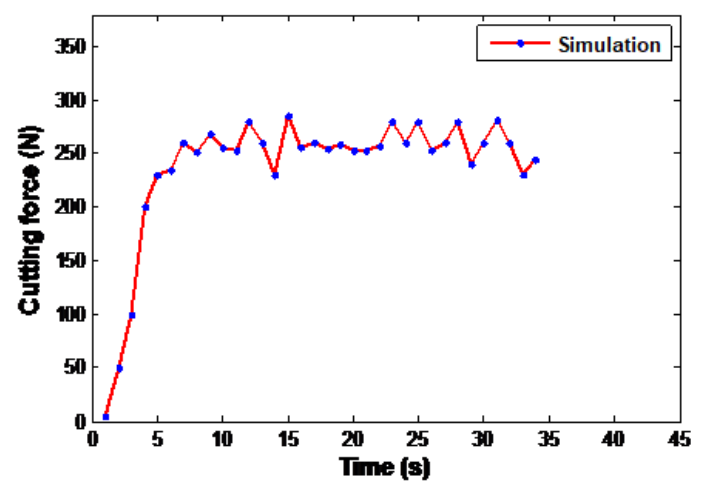

(a)

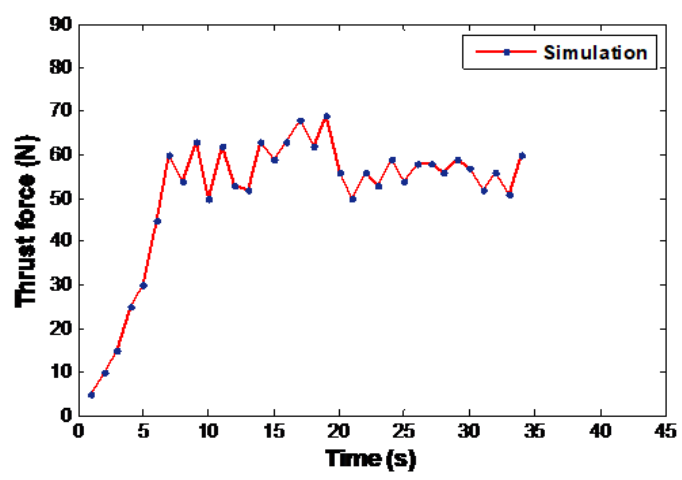

(b)

Figure 9. Simulated (a) Cutting force (b) Thrust force ( $800 \mathrm{rpm}, 0.16 \mathrm{~mm} / \mathrm{rev}, 0.25 \mathrm{~mm}$ ). 


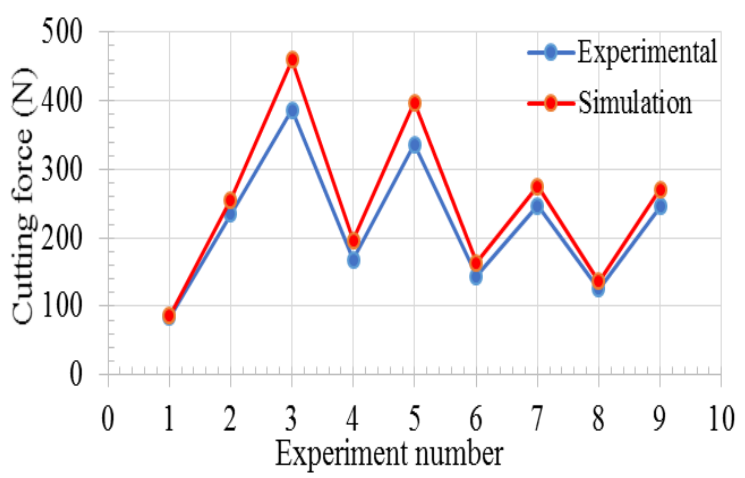

(a)

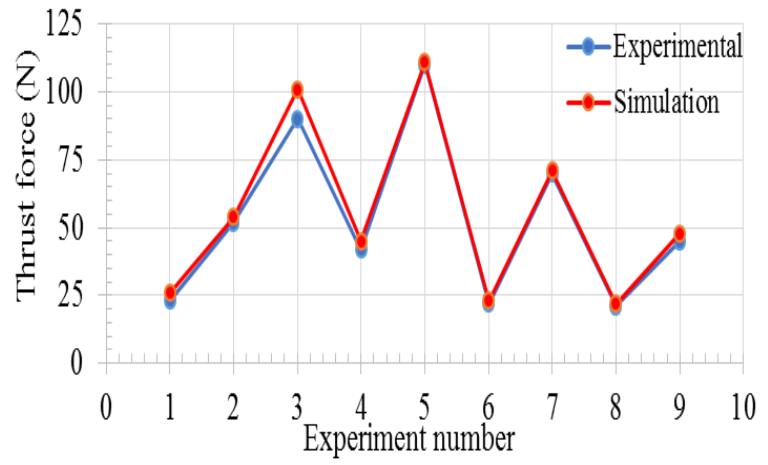

(b)

Figure 10. Comparison of simulated and experimental (a) Cutting force (b) Thrust force

Table 14. Experimental and simulation forces (coated).

\begin{tabular}{|c|c|c|c|c|c|c|c|c|c|}
\hline \multirow{2}{*}{ Exp. No } & \multicolumn{3}{|c|}{ Process Parameters } & \multicolumn{2}{|c|}{ Experimental } & \multicolumn{2}{|c|}{ Simulation } & \multicolumn{2}{|c|}{ Relative Error (\%) } \\
\hline & Speed & $\begin{array}{c}\text { Feed } \\
\text { rate }\end{array}$ & DOC & $\mathrm{F}_{\mathrm{c}}$ & $\mathrm{F}_{\mathrm{t}}$ & $\mathrm{F}_{\mathrm{c}}$ & $\mathrm{F}_{\mathrm{t}}$ & $\mathrm{F}_{\mathrm{c}}$ & $\mathrm{F}_{\mathrm{t}}$ \\
\hline 1 & 800 & 0.10 & 0.10 & 84 & 23 & 86 & 26 & 2.38 & 13.04 \\
\hline 2 & 800 & 0.16 & 0.25 & 235 & 52 & 256 & 54 & 8.92 & 3.84 \\
\hline 3 & 800 & 0.20 & 0.50 & 387 & 90 & 460 & 101 & 18.86 & 12.22 \\
\hline 4 & 1150 & 0.10 & 0.25 & 168 & 42 & 197 & 45 & 17.26 & 7.14 \\
\hline 5 & 1150 & 0.16 & 0.50 & 336 & 110 & 397 & 111 & 18.15 & 0.91 \\
\hline 6 & 1150 & 0.20 & 0.10 & 144 & 22 & 164 & 23 & 13.88 & 4.54 \\
\hline 7 & 1600 & 0.10 & 0.50 & 247 & 70 & 275 & 71 & 11.33 & 1.42 \\
\hline 8 & 1600 & 0.16 & 0.10 & 125 & 21 & 136 & 22 & 8.80 & 4.76 \\
\hline 9 & 1600 & 0.20 & 0.25 & 246 & 45 & 271 & 48 & 10.16 & 6.66 \\
\hline \multicolumn{8}{|c|}{ Average Relative Error } & 12.19 & 6.05 \\
\hline
\end{tabular}

\section{CONCLUSIONS}

In the present work, an optimal set of process parameters in turning Haynes 25 alloy with uncoated and coated carbide inserts under MQL environment is obtained using Grey relational analysis. Further, the experimental results are compared with the FE based simulated forces using 3D DEFORM machining software. Some of the specific conclusions are:

- $\quad$ Turning with uncoated inserts gave the parametric combination A2B1C1D3 to be optimum with $1150 \mathrm{rpm}$ cutting speed, $0.1 \mathrm{~mm} / \mathrm{rev}$ feed, $0.1 \mathrm{~mm}$ depth of cut, and $1.25 \%$ nanoparticle concentration. Similarly, in case of tests with coated inserts, the parametric combination A3B3C1D2 is optimum with $1600 \mathrm{rpm}$ cutting speed, $0.2 \mathrm{~mm} / \mathrm{rev}$ feed rate, $0.1 \mathrm{~mm}$ depth of cut, and $0.75 \%$ nanoparticle concentration. 
- The depth of cut is observed to be a significant parameter for both coated and uncoated experiments, and the results are satisfactorily validated through confirmation tests. The experimental data is further computed and compared using DEFORM 3D simulation. These results are found to be in good agreement with the experimental results with an average relative error of $12.40 \%$ and $11.84 \%$ for uncoated inserts and $12.19 \%$ and $6.05 \%$ for coated inserts in cutting and thrust forces respectively.

- The other responses like cutting temperature, residual stresses, chip morphology, hardness, etc. can be validated through simulations. The comparative study considering different nanoparticles (types, shape, blending, concentration, etc.) at varying coolant rate can be attempted further.

\section{REFERENCES}

Sarikaya, M. \& Güllü, A. 2014. The analysis of process parameters for turning cobalt-based superalloy Haynes 25/L 605 using design of experiment. Solid State Phenomena, 220-221: 749-753.

Sarikaya, M., Yılmaz, V. \& Güllü, A. 2016. Analysis of cutting parameters and cooling/lubrication methods for sustainable machining in turning of Haynes 25 superalloy. Journal of Cleaner Production. 133: 172-181.

Sarikaya, M. \& Güllü, A. 2015. Multi-response optimization of minimum quantity lubrication parameters using Taguchi-based grey relational analysis in turning of difficult-to-cut alloy Haynes 25. Journal of Cleaner Production.91: 347-357.

Sarikaya, M. \& Güllü, A. 2015. Examining of tool wear in cryogenic machining of cobalt-based Haynes 25 superalloy. World Academy of Science, Engineering and Technology, International Journal of Chemical, Molecular, Nuclear, Materials and Metallurgical Engineering. 9(8):984-988.

Nikhil Ranjan Dhar, Islam, M. W., Samnun Islam \& M.A.H. Mithu, 2006. The influence of minimum quantity of lubrication (MQL) on cutting temperature, chip and dimensional accuracy in turning AISI-1010 steel. Journal of Materials Processing Technology. 171(1): 93-99.

Achuthamenon Sylajakumari, P., Ramakrishnasamy, R. \& Palaniappan, G. 2018. Taguchi Grey Relational Analysis for Multi-Response Optimization of Wear in Co-Continuous Composite. Materials, 44(3): 580-587.

Aqib Mashood Khan, Munish Kumar Gupta, Hussein Hegab, M Jamil, M Mia, Ning He, Qinghua Song, Zhanqiang Liu, Caalin I Pruncu, 2020. Energy-based cost integrated modeling and sustainability assessment of Al-GnP hybrid nanofluid assisted turning of AISI52100 steel. Journal of Cleaner Production, 257(1): 1-17.

Anuj Kumar Sharma, Jitendra Kumar Katiyar, Shubrajit Bhaumik, Sandipan Roy, 2019. Influence of alumina/MWCNT hybrid nanoparticle additives on tribological properties of lubricants in turning operations. Friction, 7: 153-168.

Bouacha, K., Yallese, M. A., Mabrouki, T. \& Rigal, J. F. 2010. Statistical analysis of surface roughness and cutting forces using response surface methodology in hard turning of AISI 52100 bearing steel with CBN tool. International Journal of Refractory Metals and Hard Materials, 28(3): 349-361.

Noordin, M. Y., Venkatesh, V. C., Sharif, S., Elting, S. \& Abdullah, A. 2004. Application of response surface methodology in describing the performance of coated carbide tools when turning AISI 1045 steel. Journal of Materials Processing Technology. 145(1): 46-58.

Lalwani, D. I., Mehta, N. K. \& Jain, P. K. 2008. Experimental investigations of cutting parameters influence on cutting forces and surface roughness in finish hard turning of MDN250 steel. Journal of Materials Processing Technology.206(1-3): 167-179. 
Cakir, M. C., Ensarioglu, C. \& Demirayak, I. 2009. Mathematical modeling of surface roughness for evaluating the effects of cutting parameters and coating material. Journal of Materials Processing Technology. 209(1): 102-109.

Ashvin J. Makadia \& Nanavati, J. I. 2013. Optimization of machining parameters for turning operations based on response surface methodology. Measurement, 46(4): 1521-1529.

Routara, B. C., Sahoo, A. K., Parida, A. K. \& Padhi, P. C. 2012. Response surface methodology and genetic algorithm used to optimize the cutting condition for surface roughness parameters in CNC turning. Procedia engineering. 38: 1893-1904.

Rityuj Singh Parihar; Sahu, R. K. \& Srinivasu, G. 2017. Finite Element Analysis of Cutting Forces Generated in Turning Process using Deform 3D Software. Materials Today: Proceedings. 4(8): 8432-8438.

Zhuo Chen, Lu-Fang Qin \& Li-Juan Yang. 2006. Cutting Force Simulation of Titanium based on DEFORM3D. Proceedings of the $3^{\text {rd }}$ International Conference on Material, Mechanical and Manufacturing Engineering. 1846-1849.

Satyanarayana, K., Gopal, A. V. \& Babu, P. B. 2013. Finite Element Simulation of Cutting Forces in Turning Ti6Al4V Using DEFORM 3D. In ASME 2013 IMECHE. V02AT02A083-V02AT02A083.

Tamizharasan, T. \& Kumar, N. S. 2012. Optimization of cutting insert geometry using DEFORM-3D: Numerical simulation and experimental validation. International Journal of Simulation Modelling. 11(2): 6577 .

Slunder, C. J. 1963. Short time tensile properties of the Co-20Cr-15W-10Ni cobalt base alloy (L 605). BATTELLE MEMORIAL INST COLUMBUS OH DEFENCE METALS INFORMATION CENTER. 5667.

Rahul A. Mali, Mata Dayal Agrahari \& T. V. K. Gupta, 2019. FE based simulation and experimental validation of forces in dry turning of aluminum 7075. Materials today: Proceedings.

Hickman, R. J., Wise, J. L., Smith, J. A., Mersch, J. P., Robino, C. V. \& Arguello, J. G. 2017. Observation and simulation of motion and deformation for impact loaded metal cylinders. AIP Conference Proc. 1793, 100018: 1-6. 